\title{
CAI combustion of gasoline and its mixture with ethanol in a 2-stroke poppet valve DI gasoline engine
}

\author{
Yan Zhang*, Hua Zhao, Mohammed Ojapah, Alasdair Cairns \\ School of Engineering and Design, Brunel University, London, UK
}

\section{H I G H L I G H T S}

- CAI combustion is achieved in a 2-stroke poppet valve GDI engine.

- Gasoline and its mixture with ethanol are used as the fuel on the engine.

- The effect of ethanol content on operating range, combustion and emissions are analysed.

\section{A R T I C L E I N F O}

\section{Article history:}

Received 7 January 2013

Received in revised form 4 March 2013

Accepted 6 March 2013

Available online 25 March 2013

\section{Keywords:}

2-Stroke CAI

Poppet valve

Ethanol

E85

E15

\begin{abstract}
A B S T R A C T
Controlled Auto Ignition (CAI), also known as Homogeneous Charge Compression Ignition (HCCI), is one of the most promising combustion technologies to reduce the fuel consumption and NOx emissions. Currently, CAI combustion is constrained at part load operation conditions because of misfire at low load and knocking combustion at high load, and the lack of effective means to control the combustion process. Extending its operating range including high load boundary towards full load and low load boundary towards idle in order to allow the CAI engine to meet the demand of whole vehicle driving cycles, has become one of the key issues facing the industrialisation of CAI/HCCI technology. Furthermore, this combustion mode should be compatible to different fuels, and can switch back to conventional spark ignition operation when necessary. In this paper, the CAI operation is demonstrated on a 2-stroke gasoline direct injection (GDI) engine equipped with a poppet valve train. The results shown that the CAI combustion can be readily achieved in the 2-stroke cycle of a poppet valve engine and the range of CAI combustion can be significantly extended compared to the 4-stroke cycle operation. In addition, the effects of ethanol concentration on 2-stroke CAI operational range, combustion process, emissions and efficiencies are studied and presented.
\end{abstract}

(c) 2013 Elsevier Ltd. Open access under CC BY license.

\section{Introduction}

Controlled Auto-Ignition (CAI) or HCCI combustion has been the subject of extensive research over the last decade in the 4-stroke spark ignition engines for improved part-load fuel consumption and low exhaust emissions [1]. Many approaches have been

\footnotetext{
Abbreviations: BDC, bottom dead centre; BTDC, before top dead centre; CA10 crank angle at 10\% MFB; CA10-90, CA90-CA10; CA50, crank angle at 50\% MFB; CA90, crank angle at $90 \% \mathrm{MFB}$; CAI, Controlled Auto Ignition; $\mathrm{CO}$, carbon monoxide; $\mathrm{CO}_{2}$, carbon dioxide; E15, 15\% ethanol in gasoline; E85, 85\% ethanol in gasoline; EVC, exhaust valve closing; EVO, exhaust valve openning; GDI, gasoline direct injection; $\mathrm{HCCI}$, Homogeneous Charge Compression Ignition; HRR, heat release rate; IMEP, indicated mean effective pressure; IVC, intake valve closing; IVO, intake valve openning; MFB, mass fraction burnt; NOx, nitrous oxide; RON, research octane number; RPM, revolution per minute; SI, spark ignition; TDC, top dead centre; uHC, unburnt hydro carbon.

* Corresponding author. Tel.: +44 1895265247.

E-mail address: yan.zhang@brunel.ac.uk (Y. Zhang).
}

attempted to achieve CAI operation on the 4-stroke spark ignition engines, such as intake air heating, high compression ratio, dual fuel, recycling the exhaust gas, and so on [2]. Amongst these approaches, internally recycling the exhaust gas, such as residual gas trapping [3-6] and exhaust gas rebreathing [7], have been proved most effective in achieving CAI combustion and demonstrated their potential to be incorporated in the production gasoline engine.

One of the challenges facing the CAI combustion operation is its narrow operating load range, limited at high load by the violent combustion and at very low load by the misfire. In order to extend the load range of CAI combustion for automotive applications, a systematic research $[8,9]$ has been carried out by the authors on such combustion process in a single cylinder engine that is capable of both 4-stroke and 2-stroke operations through flexible variable valve actuation. As part of a consortium over the last several years, the authors worked with industrial partners in developing 
2/4-stroke switchable engine technologies through engine downsizing [10], from which the current research on 2-stroke CAI via poppet valve operation have been initiated and performed. In order to overcome the high $\mathrm{HC}$ and $\mathrm{CO}$ emissions and durability issues associated with the conventional crankcase scavenged 2-stroke engines, the 2-stroke poppet valve engine has been developed using the same engine architecture as the current 4-stroke engine. In addition, direct fuel injection is applied to avoid short-circuiting fuel during the scavenging process. Controlled Auto Ignition is initialized by residual gases trapped in the cylinder through incomplete scavenging, which is inherent to the 2-stroke operation. A fully variable valve train is mounted on the cylinder head so that varied amount of residual gas fraction can be obtained through con controlling scavenging process to achieve CAI combustion process at different engine operating conditions.

In this work, CAI combustion is demonstrated over different engine speed and load conditions on the 2-stroke poppet valve DI engine. Spark assisted CAI combustion and ethanol blended fuels are used to extend 2-stroke CAI operational range on the engine. Detailed analysis of combustion process, emissions and efficiencies are performed and presented in the paper.

\section{Experimental setup}

The work was performed on a single cylinder direct injection camless engine as shown in Fig. 1. The specifications of the engine are given in Table 1 . An electro hydraulic valvetrain system was used to enable independent control of valve timings and lifts. The fuel was injected by a Denso double-slit GDI injector [11], mounted under the intake port. The fuel injection pressure was set to 100 bar. The instantaneous fuel flow rate was measured by a fuel flow metre installed between the high pressure fuel pump and injector. Compressed air was supplied by an AVL supercharger system at a preset boost pressure and temperature through the closed loop control of heaters and heat exchangers. The intake mass flow rate was measured by a laminar air flow metre. Both the instantaneous intake and exhaust pressures were measured by two piezo resistive pressure transducers. The exhaust emissions were analysed by a Horiba 7170DEGR gas analyser system. The instantaneous in-cylinder pressure was measured by a piezo-electric pressure transducer.
Table 1

Engine specifications.

\begin{tabular}{ll}
\hline Bore $\times$ Stroke & $81.6 \mathrm{~mm} \times 66.94 \mathrm{~mm}$ \\
Swept volume & $0.35 \mathrm{~L}$ \\
Compression ratio & $11.78: 1$ (Geometric) \\
Combustion chamber & Pent roof/4 valves \\
Valve train & Electro-hydraulic actuation \\
Fuel injection & Direct injection \\
Fuel & Standard gasoline (RON 95), E15 and E85 \\
Injection pressure & 100 bar \\
Air/fuel ratio & Stoichiometric in exhaust \\
Intake temperature & $25^{\circ} \mathrm{C}$ \\
\hline
\end{tabular}

The heat release and combustion characteristics were calculated from the in-cylinder pressure and displayed on-line using an inhouse Labview data acquisition and combustion analysis programme [12]. The engine was installed on an automated transient engine test bed and driven by an AC motor so that both motored and fired operations could be performed.

The intake and exhaust valve timings used for the 2-stroke CAI operation in this work are illustrated in Fig. 2, in which the conventional 2-stroke spark ignition (SI) valve timings are also plotted as a reference[13,14]. In the 2 -stroke SI operation, in order to make use of the momentum of the fresh charge and achieve the post-scavenging, the exhaust valves are closed after the intake valves. In the 2-stroke CAI operation, in order to trap more burnt gas in the cylinder, both the intake and exhaust valve durations are shortened. The amount of the residual gas is controlled principally by the exhaust valve closing time which is varied depending on the requirement of the operation conditions. In the 2-stroke engine, fuel injection is timed to take place immediately after all the valves are closed in order to prevent fuel from being short-circuited to the exhaust, which is a major drawback of conventional 2-stroke engines. A lambda sensor was used to achieve the closed loop control of the air to fuel ratio so that the measured air to fuel ratio in the exhaust was maintained at stoichiometric, However, as to be discussed later, the in-cylinder air to fuel ratio was lower than the one measured by the exhaust lambda sensor because of the short-circuiting of air.
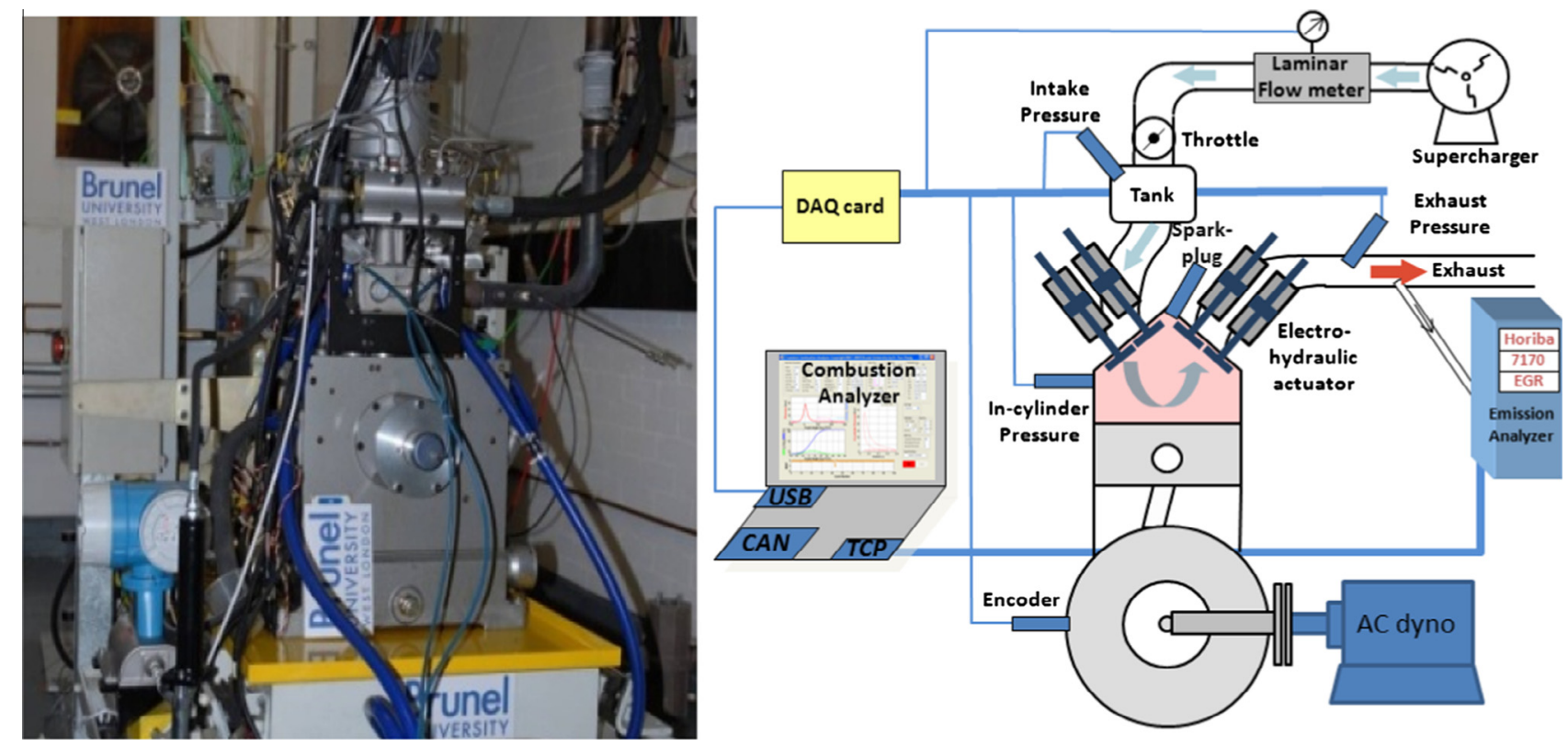

Fig. 1. Camless DI gasoline engine and the schematic of test setup. 


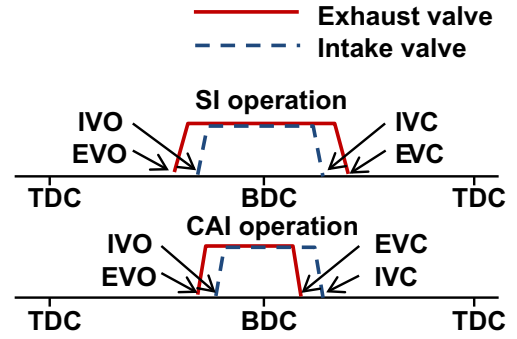

Fig. 2. Intake and exhaust valve timings for 2-stroke SI and CAI operation.

\section{Results and discussion}

\subsection{Operating range}

Firstly, the load-speed operating range of 2-stroke pure CAI of gasoline, E15 and E85 was investigated. The operating ranges of CAI combustion with exhaust lambda 1 are shown in Fig. 3. The engine speed was varied from $800 \mathrm{rpm}$ to $3000 \mathrm{rpm}$, and the load was varied from the minimum to the maximum by adjusting the boost pressure [3]. In the case of the 2-stroke poppet valve CAI operation, the engine output is determined by the scavenging ratio of the fresh air to the total in-cylinder charge. With the same valve timings, by increasing boost pressure, more fresh air is inducted and more exhaust gases are displaced, resulting higher power output. The pure CAI operation is defined as operational conditions where spark ignition does not have significant effect on the combustion phase. At low load operation, the boost pressure was lower, less exhaust gas was scavenged. The very high residual gas fraction led to unstable combustion and misfire, which limited the operation range at low load boundary. It is noted that at low speed, the more ethanol was blended in the gasoline, the more difficult the mixture could get auto ignited due to the low mixture temperature caused by the charge cooling effect of ethanol injection. Therefore, the low load boundary of E85 occurred at higher IMEP values than that of gasoline and E15 at $800 \mathrm{rpm}$. When the engine speed increased, the difference in the low load CAI limits between gasoline and its mixture with ethanol disappeared because of the reduced heat loss and higher thermal loading at higher engine speeds.

At $1000 \mathrm{rpm}$, when IMEP was over 5.3 bar, combustion became very rapid and the rate of pressure rise exceeded the pre-defined knock limit of 5 bar/CA. This is because the combustion process was accelerated due to the higher in-cylinder temperature and less dilution of the residual gases at higher load conditions, as shown in

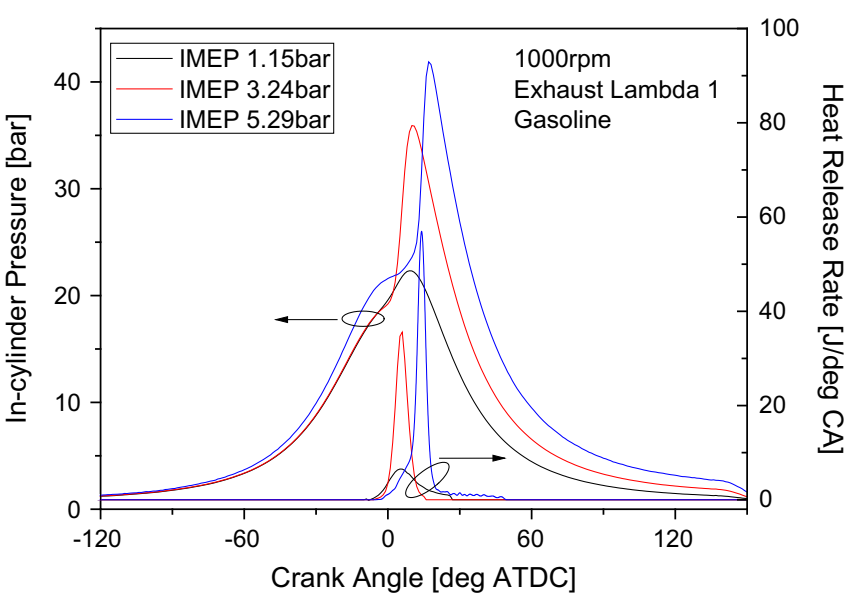

Fig. 4. In-cylinder pressure and heat release rate at $1000 \mathrm{rpm}$ and different loads.

Fig. 4. It can be seen that the knock limit was extended by $0.7-$ 6.2 bar IMEP when blending 15\% ethanol in gasoline. E85 further extended the load range by $3-8.5$ bar IMEP. This is a result of slower heat release rate of ethanol than gasoline, as shown in Fig. 5. In the case of gasoline, the upper load boundary moved up slightly as the engine speed was changed from $800 \mathrm{rpm}$ to $1000 \mathrm{rpm}$, as to be explained later.

For all three fuels, it is noted that the upper load limits would fall with the engine speed. For gasoline and E15, this occurred at $2000 \mathrm{rpm}$ and $1500 \mathrm{rpm}$ respectively, whilst E85 fuel exhibited continued decrease in the upper load limit of CAI operation with the engine speed. This can be explained by the flow characteristics of the camless valve actuation system. Because the valves were operated independently from the engine's own rotation by the electro-hydraulic actuation, for a given intake and exhaust valve profile, the valve opening durations remained constant in milleseconds but they became less in terms of crank angles as the engine speed increased. In addition, due to the finite opening and closing speeds of the electro-hydraulic valves, the valves could not reach their maximum lift at $1500 \mathrm{rpm}$ and above in the twostroke mode. Although the valve durations were increased at higher engine speed operations to compensate for the reduction in the air flow rate caused by the reduced valve lift, it's still not sufficient for the high load operation. This resulted in the gas exchange limit at higher speeds on the CAI operating range. Because ethanol has a lower stoichiometric air fuel ratio than gasoline, the addition of

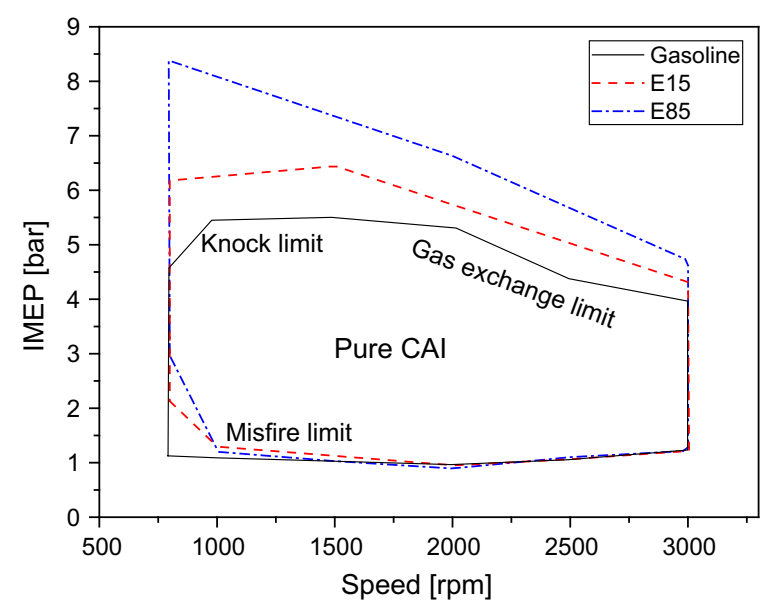

Fig. 3. Operating range of 2-stroke CAI fuelled with gasoline, E15 and E85.

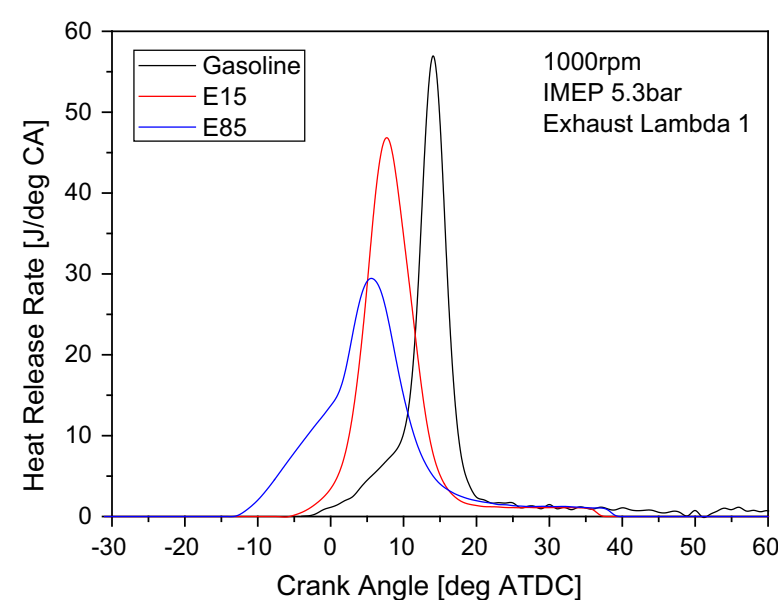

Fig. 5. Heat release rate of gasoline, E15 and E85 at $1000 \mathrm{rpm}$ and 5.3 bar IMEP. 
ethanol reduced the amount of air required for combustion and hence could produce more output for the same amount of air trapped in the cylinder than gasoline. This is illustrated by the air flow rate values for gasoline (Fig. 6a), E15 (Fig. 6b), and E85 (Fig. 6c). Therefore, at $3000 \mathrm{rpm}$, E15 extended the gas exchange limit by half bar IMEP and E85 1.5 bar IMEP, compared with gasoline CAI operating range.

In addition to the pure CAI operating range, spark assisted CAI combustion was used to extend the operational range of low temperature combustion with high dilution [15]. Fig. 7 shows the extended 2-stroke CAI operating range with the spark assisted CAI operation. Although there was no noticeable effect of spark ignition seen on the combustion process within the pure CAI operating range, the spark was kept on but the spark timing was set at TDC. The pure CAI operating zone was sandwiched by two regions of the spark assisted CAI operation, where the combustion could not be started or completed without spark. However, the effects of the spark on the spark assisted CAI operation zone at higher load and idle conditions are different, which can be seen from the spark timing values shown in Fig. 7. In the high load spark assisted CAI operation, the combustible charge of air/fuel mixture became higher and less burned gases were trapped. This led to lower compressed charge temperature than the autoignition temperature and required spark ignition to ignite the mixture. The combustion process is characterised as a slow start in the first portion (flame propagation) and this is followed by a rapid heat release process (autoignition at multi-points), as shown in Fig. 8a. The spark timing, however, was retarded to prevent knocking combustion. In the spark assisted CAI operation at idle, the spark timing was advanced before TDC to help to stabilize the combustion process, which would suffer from slow combustion due to high dilution rate, as shown in Fig. $8 \mathrm{~b}$.

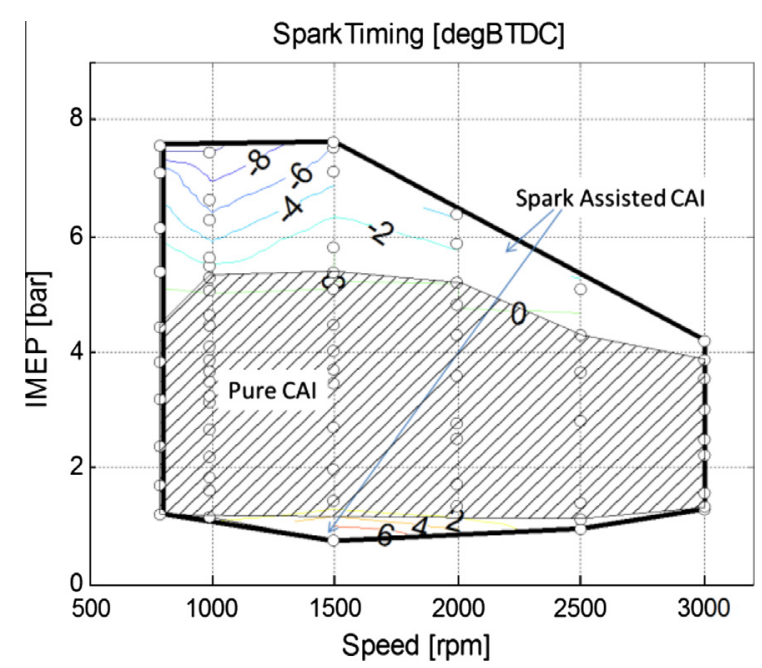

Fig. 7. Spark timing in 2-stroke spark assisted CAI operational range (Gasoline).

\subsection{Effects of ethanol concentration on 2-stroke CAI combustion process}

Fig. 9 shows 50\% mass fraction burnt crank angle (CA50) as a function of the engine load, IMEP, at $2000 \mathrm{rpm}$ with gasoline, E15 and E85. It can be seen that the combustion phase was retarded with increasing engine load in most cases. As explained above, load in the 2-stroke CAI operation was determined by the scavenging rate. As the load increased, there were more fresh charge but less residual gas trapped, resulting in the lower in-cylinder temperature. Therefore, the start of autoignition combustion was delayed

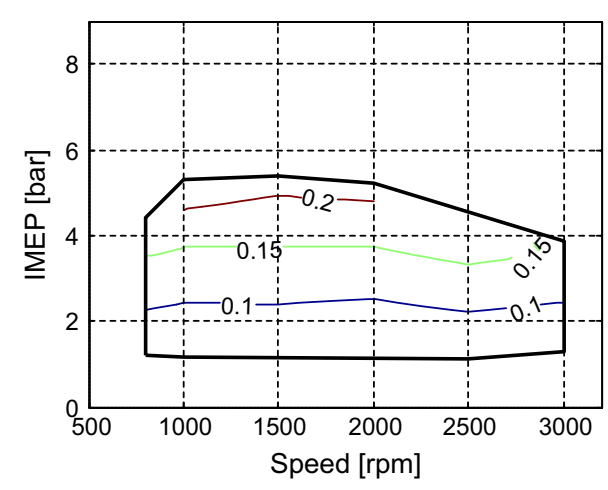

(a) Gasoline

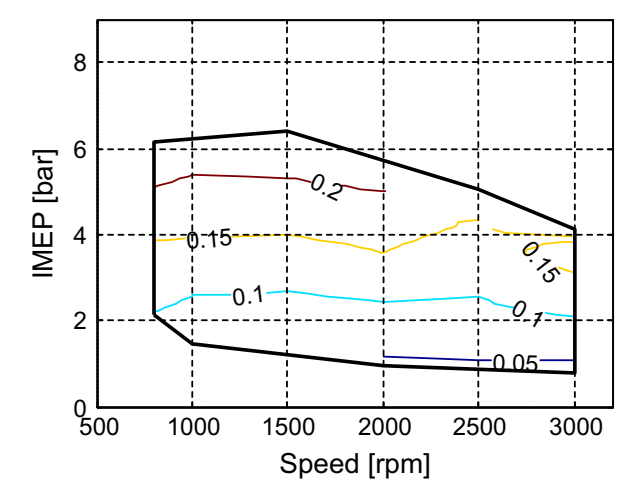

(b) $E 15$

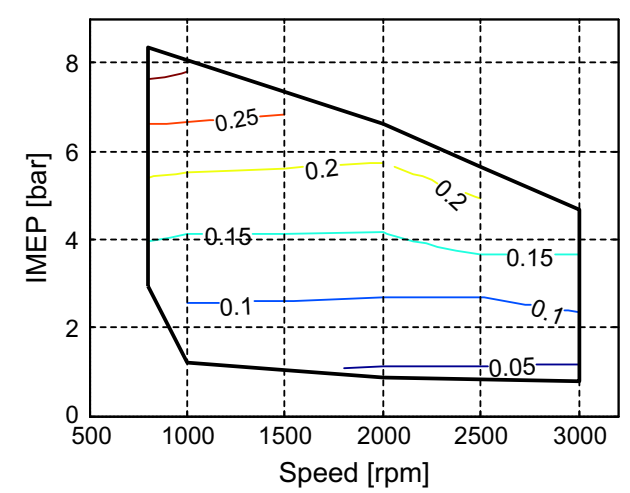

(c) $E 85$

Fig. 6. Air flow rate (g/cycle) over 2-stroke CAI operating range. 


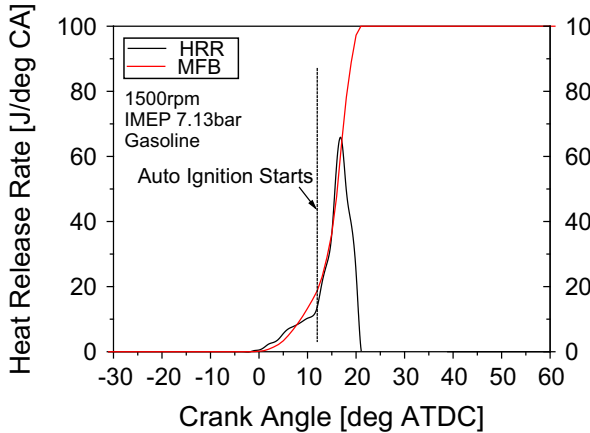

(a)

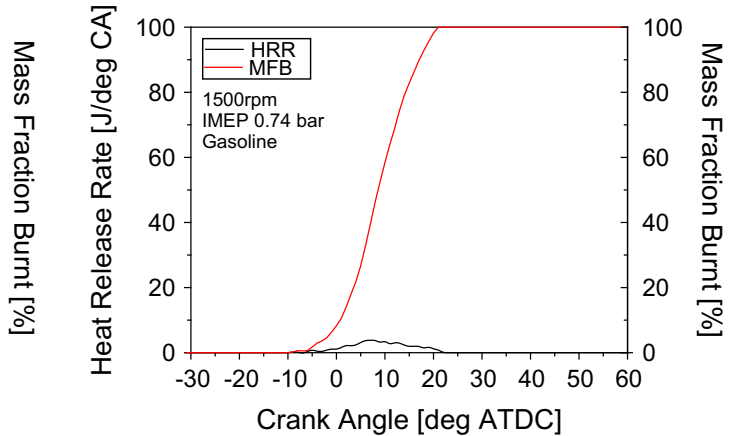

(b)

Fig. 8. Heat release rate and mass fraction burnt of spark-assisted CAI.

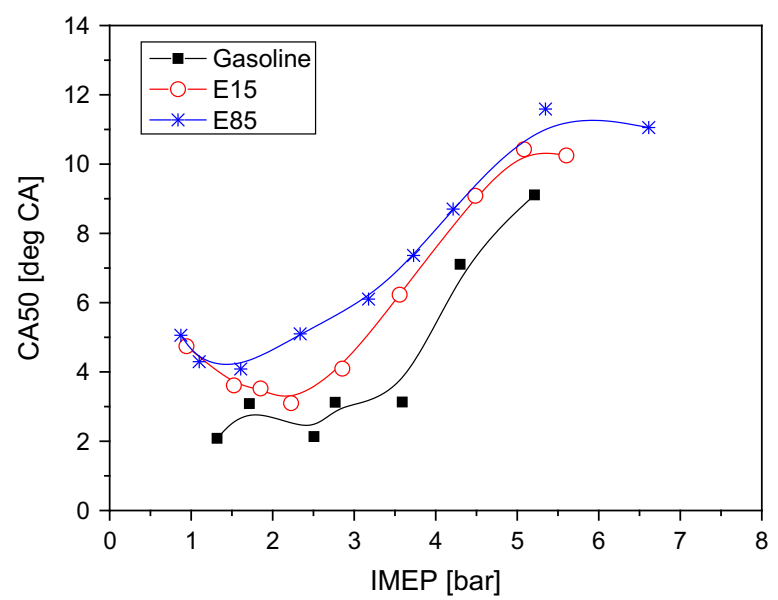

Fig. 9. CA50 in 2-stroke CAI operation at $2000 \mathrm{rpm}$.

until the charge temperature was compressed to the autoignition temperature. At the highest load conditions, autoignition could not start and spark ignition was introduced after TDC to initiate the combustion process. At the low load conditions, the start of combustion for E15 and E85 advanced slightly as the load was changed from 1 bar IMEP to 2 bar IMEP. At such low load, the largest amount of burned gas was trapped and the burned gas temperature was at their lowest value. In addition, there were a relative large percentage of unburned or partially burned fuels in the trapped charge which would contribute to the autoignition chemistry leading to the start of the high temperature combustion reactions. Since the autoignition process is affected by the charge dilution, temperature, and chemical species in the cylinder charge, the small changes observed could have been caused by any of these factors. Further studies would be needed to understand the relative importance of each effect.

As shown in Fig. 10, the combustion duration of all three fuels initially decreased with load due to lower dilution effect by the reduced amount of burned gas trapped in the cylinder at higher load. Beyond 4.2 bar IMEP, E15 and E85 showed increased combustion duration as a result of spark assisted CAI and retarded combustion phase. As shown in Fig. 3, at such high load conditions, spark ignition was critical to initiate the combustion process in the form of flame propagation. Because of the relatively high temperature of the end gas region, multiple autoignition combustion would take place in conjunction with the flame propagation. This can be illustrated by the mass fraction burned curves at 4.2 bar and 6.6 bar IMEP values for E85 plotted in Fig. 11. It can be seen that the heat

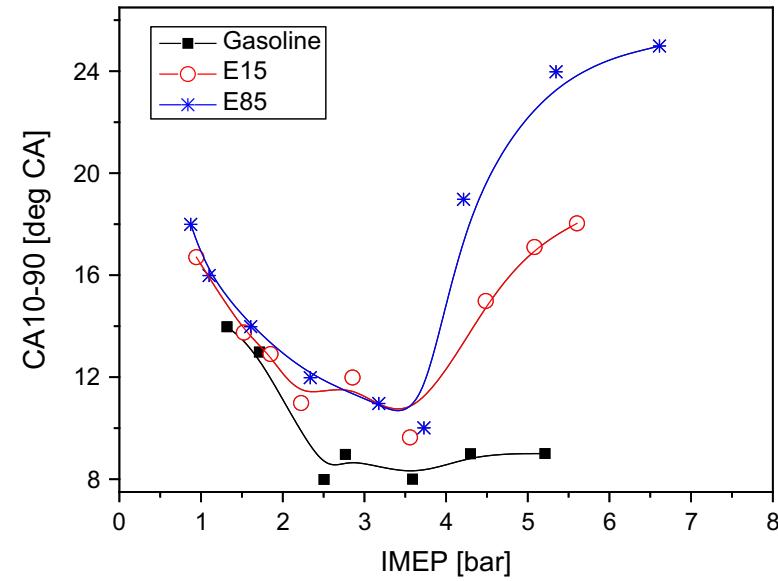

Fig. 10. CA10-90 in 2-stroke CAI operation at $2000 \mathrm{rpm}$.

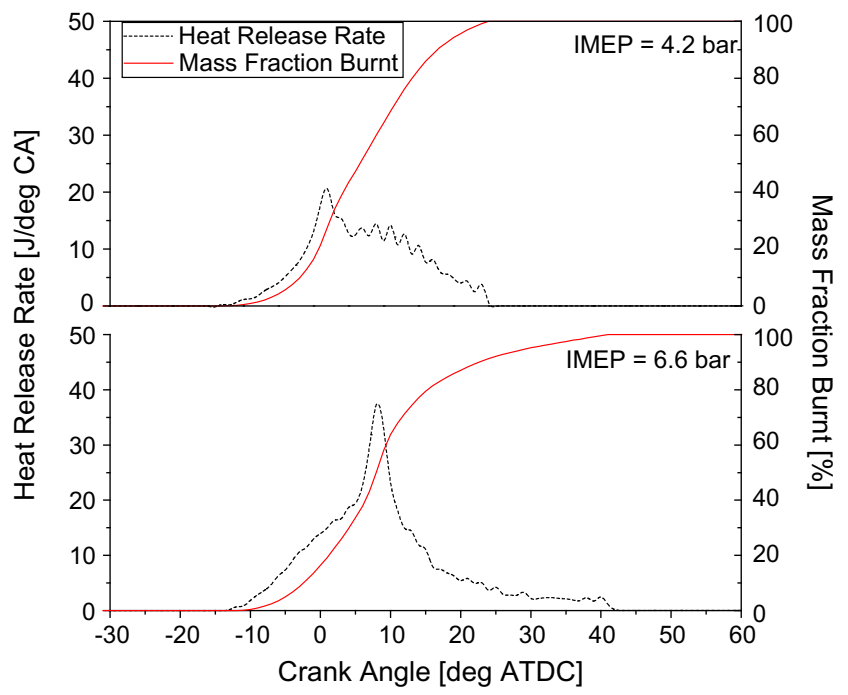

Fig. 11. Heat release rate and mass fraction burnt of E85 at $2000 \mathrm{rpm}$.

release process is characterised by a relatively slow first part and then followed by a faster second part. As previous studies have shown $[16,17]$, the two stage heat release process was a result of the hybrid combustion of flame propagation and multiple autoignition burning in the spark assisted CAI region. As the load increased beyond 4.2 bar IMEP, flame propagation became dominant over 
the multiple autoignition combustion and accounts for a greater part of the combustion and heat release process, resulting in an increase in the overall combustion duration.

\subsection{Emissions}

Fig. 12 shows the unburned hydrocarbon (uHC) emissions as a function of engine output at $2000 \mathrm{rpm}$. The presence of ethanol reduced the uHC emissions throughout the load range. E85 produced about $50 \%$ less uHCs than gasoline. As the combustion temperature became higher with load, more complete combustion could take place and hence less uHC emissions. As reported by the authors [18], the uHC emissions from the 2-stroke CAI combustion was not much different from the 4-stroke SI operations in the same engine. One major source of uHCs from this engine is due to the inadequate optimisation of fuel spray and combustion chamber design, which resulted in fuel impingement on the piston and cylinder wall. It is expected that multiple fuel injection from a fast acting injector at higher injection pressure together with an appropriate designed piston top would lead to significant reduction in the uHC emissions.

The CO emission results in Fig. 8 show that E15 and E85 fuels produce less $\mathrm{CO}$ emissions, particularly at high load conditions, because of the more effective oxidation reactions of oxygenated ethanol. It is noted that gasoline produced significantly more $\mathrm{CO}$ at higher load whilst the CO emissions from E15 and E85 fuels remained relatively insensitive to the load. In order to explain the results, it is necessary to understand the air short-circuiting and its effect on in-cylinder air/fuel ratio.

As Fig. 2 shows, there was an overlap period between the intake process and exhaust process in the 2-stroke CAI mode operation. During this overlap period, it is likely that a fraction of air could flow directly out of the exhaust valves, a phenomenon known as air short-circuiting. In order to quantify the air short-circuiting rate, a fast response $\mathrm{CO}_{2}$ analyser was adopted to measure the cycle-resolved air short-circuiting rate [18]. The in-cylinder air/fuel ratio was then deducted from the exhaust lambda value. As shown in Fig. 13, the short-circuiting rate increased with the engine load or boost pressure, combustion took place with richer fuel and air mixture at higher load, resulting in higher $\mathrm{CO}$ emissions with gasoline as shown in Fig. 14. When ethanol was introduced, the stoichiometric air to fuel ratio decreased. Hence less air at lower boost pressure was needed, reducing the short-circuiting rate. At low loads, the effect of ethanol on improving $\mathrm{CO}$ emissions becomes less significant because of the lower short-circuiting rate and lower combustion temperature of ethanol.

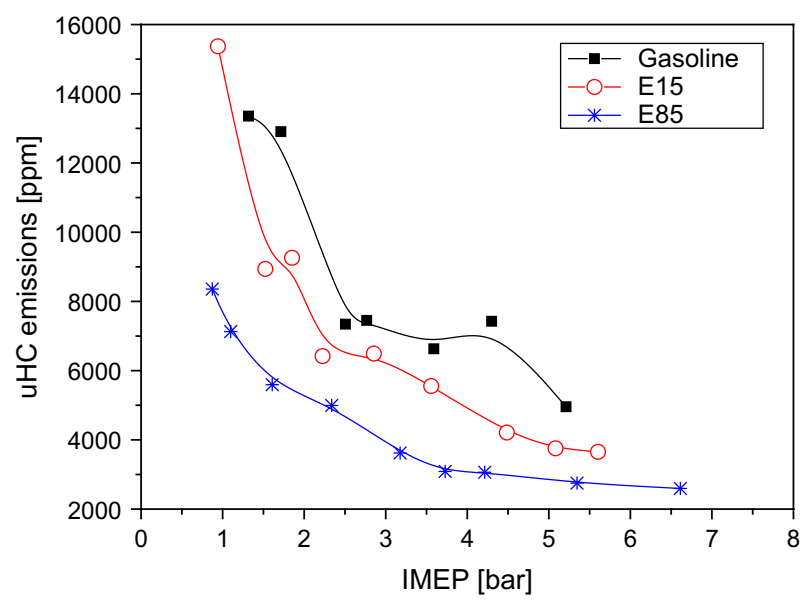

Fig. 12. uHC emissions in 2-stroke CAI operation at $2000 \mathrm{rpm}$.

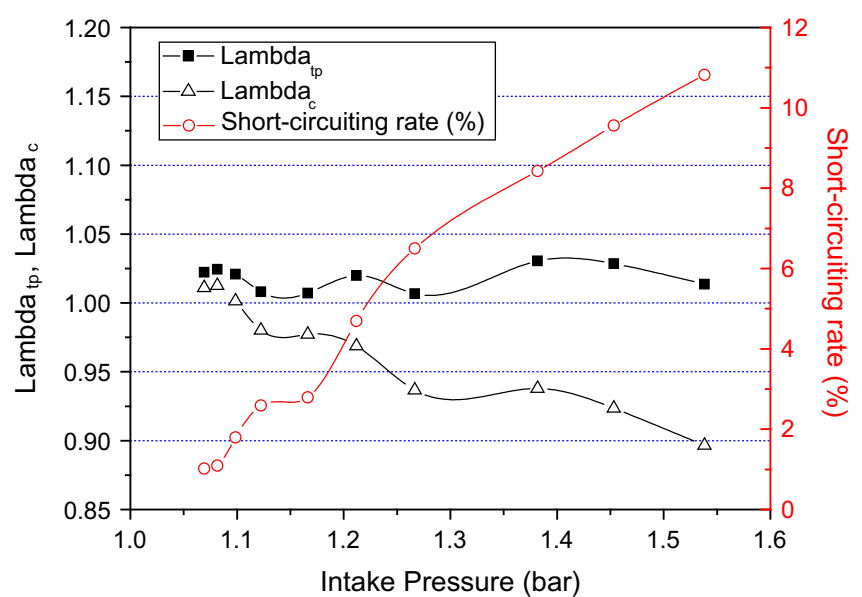

Fig. 13. The effect of short-circuiting on in-cylinder lambda (Lambda ${ }_{c}$ ) and exhaust lambda (Lambda $\left.\mathrm{tp}_{\mathrm{p}}\right)$.

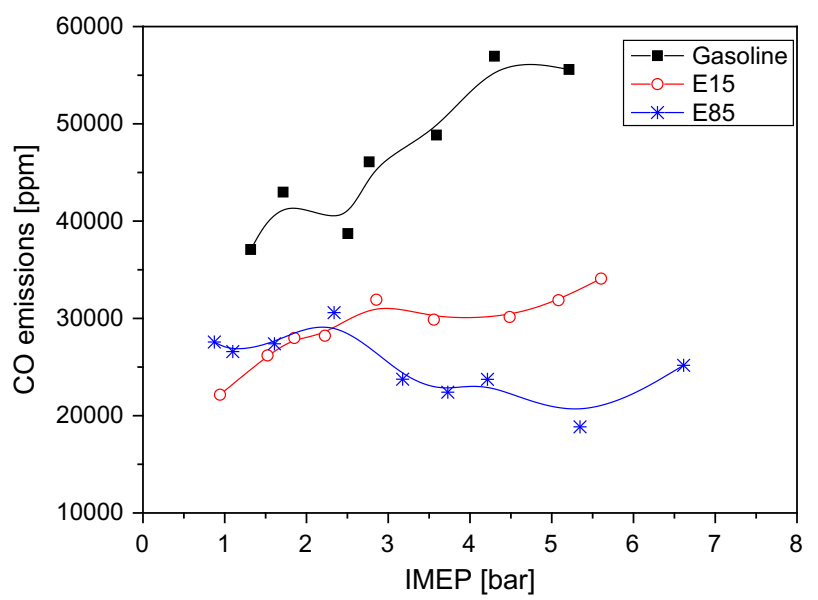

Fig. 14. CO emissions in 2-stroke CAI operation at $2000 \mathrm{rpm}$.

Fig. 15 shows the NOx emissions in the 2-stroke CAI operation fuelled with gasoline, E15 and E85 at an engine speed of $2000 \mathrm{rpm}$. E85 had significant effect on reducing NOx emissions at high loads mainly due to the cooling effect of ethanol. However, this effect became less significant at low loads as the combustion temperature and NOx emission were very low (less than $100 \mathrm{ppm}$ ).

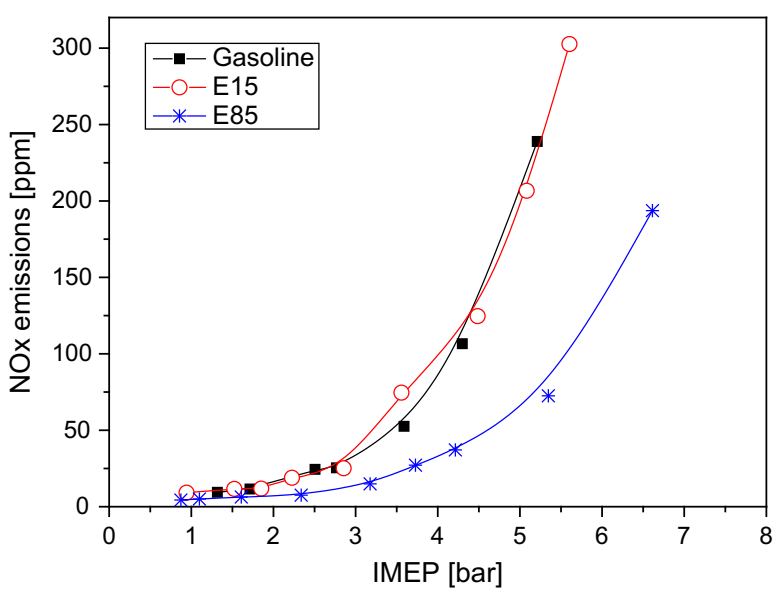

Fig. 15. NOx emissions in 2-stroke CAI operation at $2000 \mathrm{rpm}$. 


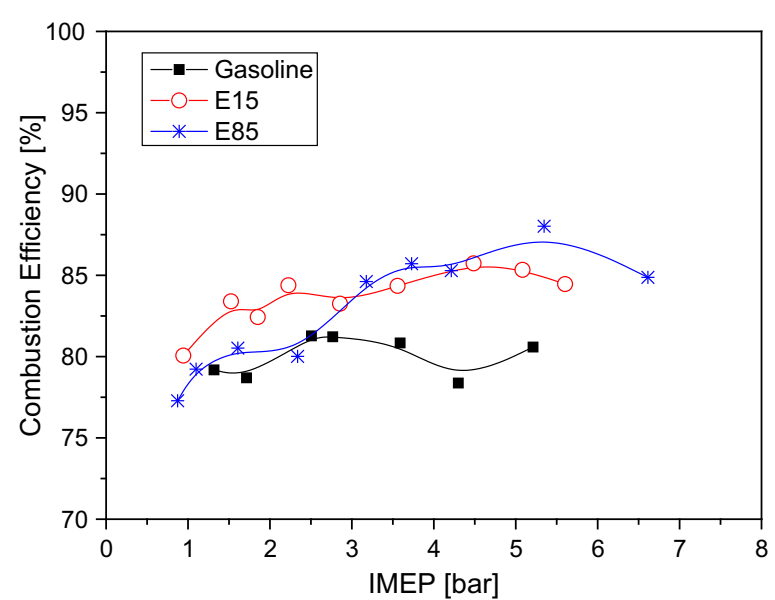

Fig. 16. Combustion efficiency in 2-stroke CAI operation at $2000 \mathrm{rpm}$.

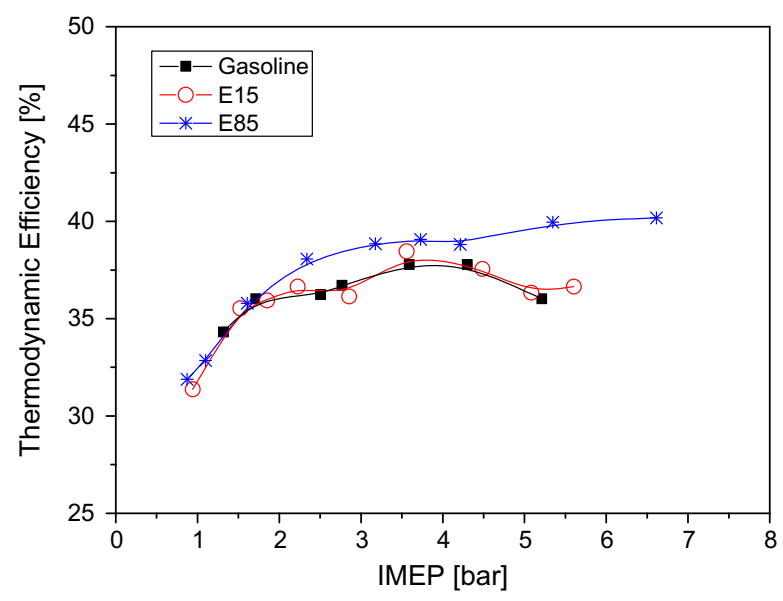

Fig. 17. Thermodynamic efficiency in 2-stroke CAI operation at $2000 \mathrm{rpm}$.

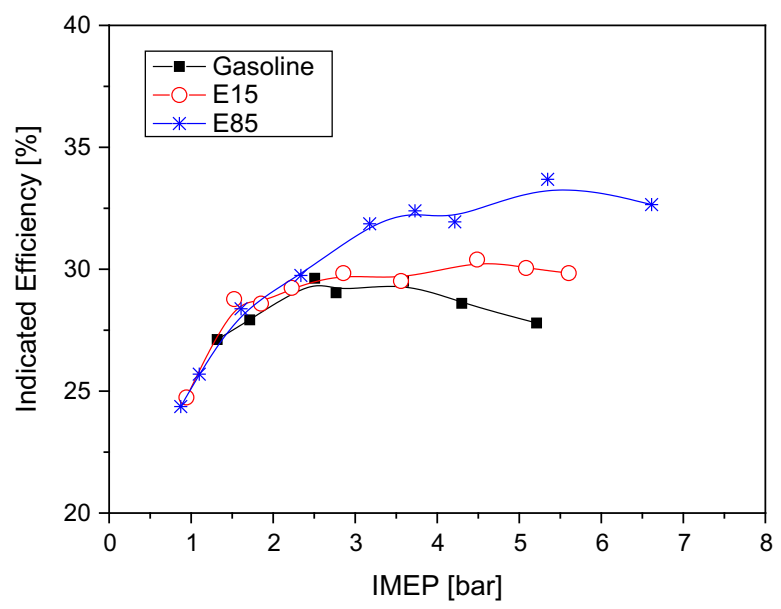

Fig. 18. Indicated fuel conversion efficiency in the 2-stroke CAI operation at $2000 \mathrm{rpm}$.

\subsection{Efficiencies}

In order to compare the fuel economy and take into account of the different calorific values of gasoline and ethanol, combustion efficiency, thermodynamic efficiency and indicated fuel conversion efficiency are calculated and analysed for gasoline and its blends with ethanol.

Combustion efficiency is defined as the ratio of the heat leased from the fuel to the chemical energy of the fuel, and its formula is:

$\eta_{\text {Combustion }}=\frac{Q_{1}}{E_{\text {fuel }}}=1-\frac{G_{\mathrm{CO}} * 10.1+G_{H C} * 43}{\text { Fuelflowrate } * \text { LHV }}$

where $Q_{1}$ is the heat leased by fuel, $E_{f u e l}$ is the chemical energy of fuel, $G_{\mathrm{CO}}$ is $\mathrm{CO}$ emission mass flow rate, $G_{H C}$ is $H C$ emission mass flow rate, $L H V$ is low heat value of fuel, Thermodynamic efficiency is defined as the ratio of the gross work of the cycle to the heat leased by fuel, and its formula is:

$\eta_{\text {Thermodynamic }}=\frac{W_{\text {Gross }}}{Q_{1}}=\frac{\mathrm{IMEP}_{\text {Gross }} * V_{s}}{\text { Fuelflowrate } * L H V * \eta_{\text {Combustion }}}$

where $W_{\text {Gross }}$ is the gross work of the cycle, IMEP $\mathrm{Iross}_{\text {G }}$ is the gross indicated mean effective pressure, $V_{s}$ is the displacement volume, Indicated efficiency is defined as the ratio of the gross work of the cycle to the chemical energy of fuel, and its formula is:

$\eta_{\text {Indicated }}=\frac{W_{\text {Gross }}}{E_{\text {fuel }}}=\eta_{\text {Thermodynamic }} * \eta_{\text {Combustion }}$

Fig. 16 shows their combustion efficiency values in the 2-stroke CAI operation at $2000 \mathrm{rpm}$. It can be seen that the combustion efficiency is relatively low on this engine due to the rich mixture in the combustion chamber caused by the short-circuiting of the air and non-optimized injection system, as mentioned above. However, compared with gasoline, the combustion efficiency was improved by $3-5 \%$ by blending $15 \%$ ethanol in the gasoline. Further increasing ethanol concentration to $85 \%$ in the fuel could further improve the combustion efficiency at high load operation, but at low load operation the low temperature of the mixture caused by the higher latent heat value of ethanol led to lower combustion efficiency. This is also reflected by the higher CO emissions of E85 at low load shown in Fig. 14.

The best thermodynamic efficiency was obtained with E85 at high load operation, shown in Fig. 17. This was the result of optimised combustion phasing as shown in Fig. 9 and reduced heat loss during the combustion process because of the lower charge and combustion temperature of ethanol. The presence of ethanol had little effect at low load operations.

Fig. 18 shows the combined effect of combustion efficiency and thermal efficiency, as measured by the indicated fuel conversion efficiency. At 5 bar IMEP and $2000 \mathrm{rpm}$, the indicated efficiency can be improved by $5 \%$ with E85 and 2\% with E15.

\section{Conclusions}

In this paper, CAI combustion has been demonstrated on a poppet valve DI gasoline engine operating in the 2-stroke cycle. Gasoline and its mixture with ethanol, E15 and E85, were used and their ranges of CAI operations were determined as a function of the engine speed and load. Their combustion and heat release characteristics, emissions, and their combustion and thermodynamic efficiencies were determined and analysed. The results show that

1. 2-stroke CAI combustion operation can be achieved over a wide range of engine speed and load conditions, including idle operations that could not be achieved with 4-stroke operations.

2. The presence of ethanol allowed CAI combustion to be extended to higher load conditions. In the case of E85 the maximum IMEP of 8.4 bar was obtained at $800 \mathrm{rpm}$, significantly higher than the 4-stroke equivalent. Further improvement in the high load range at higher engine speeds 
can be achieved with a faster camless system or mechanical camshafts.

3. CO, uHC and NOx emissions are significantly reduced by injecting ethanol blended fuels. E85 has greater effect on the emission reduction than E15.

4. Both combustion efficiency and thermodynamic efficiency are improved by the presence of ethanol because of the optimum combustion phasing and lower heat loss. E85 improved indicated fuel conversion efficiency by over $5 \%$ at $2000 \mathrm{rpm}$.

The above results were obtained by keeping the relative air to fuel ratio to stoichiometric in the engine exhaust. Because of the air short-circuiting effect, the in-cylinder air to fuel ratio was lower and fuel rich combustion took place. Further works are currently being carried out to minimize the fuel consumption by increasing the air to fuel ratio at each operating condition. In addition, future improvement in the fuel injector and combustion chamber design are expected to further reduce the $\mathrm{uHC}$ and $\mathrm{CO}$ emissions and improve the thermal efficiency and indicated fuel conversion efficiency, making the 2 -stroke poppet valve engine a viable low emission and high efficiency IC engine for automotive applications.

\section{Acknowledgement}

This work was supported by the Engineering and Physical Sciences Research Council (Grant Number EP/F058942/1).

\section{References}

[1] Zhao $\mathrm{H}$, editor. HCCI and CAI engines for the automotive industry. Cambridge: Woodhead Publishing; 2007.

[2] Zhao F, Asmus TW, Assanis DN, Dec JE, Eng JA, Najt PM. Homogeneous charge compression ignition ( $\mathrm{HCCI}$ ) engines, key research and development issues. SAE Publication PT-94, Society of Automotive Engineers; 2003.
[3] Lavy J et al. Innovative ultra-low NOx controlled auto-ignition combustion process for gasoline enignes: the 4-SPACE project, SAE paper 2000-01-1837; 2000.

[4] Koopmans L et al. A four stroke camless engine, operated in homogeneous charge compression ignition mode with commercial gasoline, SAE paper 200101-3610; 2001.

[5] Law D et al. Controlled combustion in an IC-engine with a fully variable valve train, SAE paper 2001-01-0251; 2001.

[6] Zhao $\mathrm{H}$ et al. Performance and analysis of a 4-stroke multi-cylinder gasoline engine with CAI combustion, SAE paper 2002-01-0420; 2002.

[7] Fuerhapter A et al. CSI - controlled auto ignition - the best solution for the fue consumption - versus emission trade-off?, SAE paper 2003-01-0754; 2003

[8] Zhang Y, Zhao $\mathrm{H}$, et al. Effects of injection timing on CAI operation in a 2/4stroke switchable GDI engine, SAE paper 2011-01-1773; 2011.

[9] Zhang Y, Zhao, $\mathrm{H}$ et al. Experiment and analysis of a direct injection gasoline engine operating with 2-stroke and 4-stroke cycles of spark ignition and controlled auto-ignition combustion, SAE paper 2011-01-1774; 2011.

[10] Osborne RJ, Stokes J, Lake TH, et al. Development of a two-stroke/four-stroke switching gasoline engine - the 2/4SIGHT concept, SAE paper 2005-01-1137; 2005.

[11] Sadakane S et al. Development of a new V-6 high performance stoichiometric gasoline direct injection engine, SAE paper 2005-01-1152; 2005.

[12] Zhao $\mathrm{H}$, Ladommatos $\mathrm{N}$. Engine combustion instrumentation and diagnostics, P29, SAE; 2001.

[13] Heywood JB, Sher E. The two-stroke cycle engine, P3, SAE; 1999.

[14] Heywood JB. Internal combustion engines fundamentals, P29. McGraw-Hill Inc.; 1988.

[15] Zhang Y, Zhao H, Ojapah M, Cairns A. Analysis of CAI/HCCI combustion in a 2stroke poppet valve engine, In: ImechE conference: internal combustion engines: improving performance, fuel economy and emissions, London; 2011.

[16] Yang C, Zhao H, Megaritis T. In-cylinder studies of CAI combustion with negative valve overlap and simultaneous chemiluminescence analysis, SAE technical paper 2009-01-1103; 2009. doi:10.4271/2009-01-1103.

[17] Zhang Y, Zhao H, Xie H, Hou S, Yang C. Characterization and heat release model development of SI-CAI hybrid combustion and its application to a 4-stroke gasoline engine operating with highly diluted mixtures, In: 33rd International symposium of combustion, 3E07, Beijing (China): Tsinghua University; 2010.

[18] Zhang Y, Zhao H. Measurement of short-circuiting and its effect on CAI or HCCI combustion in a two-stroke poppet valve engine. Proc Inst Mech Eng, Part D: J Automob Eng 2012. http://dx.doi.org/10.1177/095440701143425. 